\title{
EFEITO DO PAGAMENTO POR QUALIDADE DO LEITE NA RENTABILIDADE DA ATIVIDADE LEITEIRA
}

\section{Effect of payment for milk quality on the profitability of dairy farming}

\author{
Fernando Etiene Pinheiro Teixeira Júnior ${ }^{{ }^{*}}$, Marcos Aurélio Lopes ${ }^{2}$, \\ José Reinaldo Mendes Ruas ${ }^{3}$
}

\begin{abstract}
RESUMO
Analisou-se, por meio de simulação, o efeito do pagamento por qualidade do leite na rentabilidade da atividade leiteira de um sistema de produção de leite com vacas F1 Holandês x Gir. Durante o período chuvoso, na época do verão, as vacas foram mantidas em pastos e, durante o período da seca, foram confinadas com o uso da cana-de-açúcar in natura enriquecida com ureia e sulfato de amônio. A referência zootécnica foi do rebanho da Fazenda Experimental de Felixlândia (FEFX) da Empresa de Pesquisa Agropecuária de Minas Gerais (EPAMIG), localizada no município de Felixlândia-MG, região central do estado. O inventário bem como as despesas, as receitas e os demais dados foram cadastrados no software CUSTO BOVINO LEITE 1.0, visando obter a análise de rentabilidade. A utilização de práticas zootécnicas que possibilitam melhorias na qualidade do leite proporciona um diferencial da remuneração, advinda das bonificações, incrementa os resultados econômico-financeiros e melhora a rentabilidade do sistema de produção de leite analisado.
\end{abstract}

Palavras-chave: bovinocultura leiteira; lucratividade; remuneração; simulação.

1 Universidade Estadual de Montes Claros, Departamento de Ciência da Administração, Caixa Postal 126, 39401-089, Montes Claros, MG, Brasil. E-mail: fernandoetiene82@hotmail.com

2 Universidade Federal de Lavras, Departamento de Medicina Veterinária, Caixa Postal 3037, 37200-000, Lavras, MG, Brasil.

3 Empresa de Pesquisa Agropecuária de Minas Gerais (EPAMIG).

* Autor para correspondência.

Recebido / Received: 06/10/2014

Aprovado / Approved: 26/01/2015 


\begin{abstract}
Analyzed, by means of simulation, the effect of payment for milk quality on the profitability of dairy farming a system of milk production with F1 Holstein x Gir cows. During the rainy season, in the summer season, cows were kept on pastures and, during the dry season, were confined with use of cane sugar in natura enriched with urea and ammonium sulfate. The zootechnical reference was composed of herd of F1 Holstein x Gir cows of the Experimental Farm Felixlândia (FEFX) of the Agricultural Research Corporation of Minas Gerais (EPAMIG), located in the municipality of Felixlândia-MG, central region of the state. The inventory and expenditure, revenue and other data were registered on COST BOVINE MILK 1.0 software, to obtain profitability analysis. The use of zootechnical practices which enable improvements in the quality of milk provides a differential remuneration, arising from subsidies; increases the economic-financial results and improves the profitability of milk production system analyzed.
\end{abstract}

Keywords: dairy cattle; profitability; remuneration; simulation.

\section{INTRODUÇÃO}

Tendo em vista as necessidades e desejos dos consumidores e as exigências das agroindústrias por um produto de melhor qualidade torna-se necessária uma adequação dos produtores de leite a esta nova realidade. A partir daí, dada à demanda de toda a cadeia produtiva do leite, por iniciativa do Ministério da Agricultura, Pecuária e Abastecimento (MAPA), surgiu, em 1996, na Embrapa - Gado de leite, o Programa Nacional de Melhoria da Qualidade do Leite (PNQL) com os objetivos de promover a melhoria da qualidade do leite e derivados, garantir a saúde da população e aumentar a competitividade dos produtos lácteos em novos mercados. Como parte integrante do PNQL está em vigor a IN 62/2011 (BRASIL, 2011), que exige do produtor o atendimento de padrões mínimos de qualidade do leite na composição e no aspecto sanitário, verificada por meio de análises laboratoriais sistemáticas. Assim, no cumprimento desta normativa, pode haver penalização ou bonificação para o produtor.

Assim sendo, constata-se que vem ocorrendo uma transformação profunda no agronegócio do leite e, consequentemente, nos sistemas de produção de leite do Brasil no tocante à sua qualidade. Hoje o produtor se depara com duas situações, ou ele melhora a qualidade do produto para, além de se beneficiar da remuneração, manter-se competitivo, ou ele continua produzindo de forma tradicional, sem preocupações e fica fadado a ser "eliminado" do sistema. Segundo Cardoso et al. (2004), no Brasil há alguns padrões mínimos de qualidade do leite e caso não sejam atendidos ocasionarão penalizações no valor pago ao produtor. Entretanto, não há uma política bem estabelecida de pagamento diferenciado.

Contudo, a remuneração do leite por qualidade deve ser perseguida pelo produtor, tanto nos procedimentos de produção leiteira como na luta pelos seus interesses diante da indústria de laticínios e do governo. Entretanto, fica a dúvida quanto à eficiência econômico-financeira de se almejar e atingir a qualidade exigida, quando se leva em conta a bonificação determinada pelo mercado.

Com base nos resultados alcançados com a melhora na qualidade do leite consoante com a bonificação por qualidade, objetivou-se 
analisar o efeito do pagamento por qualidade do leite na rentabilidade de um sistema de produção com vacas F1 Holandês $x$ Zebu. Esse cruzamento (F1) proporciona ao indivíduo reunir características dos seus progenitores (Holandês e Zebu) e explorar ao máximo a heterose, resultando num melhor desempenho produtivo do que a média dos seus pais.

\section{MATERIAL E MÉTODOS}

Analisou-se, por meio de simulação, o efeito do pagamento por qualidade de leite na rentabilidade da atividade leiteira de um sistema de produção de leite com vacas F1 Holandês x Zebu.

A referência zootécnica foi do rebanho composto por vacas F1 Holandês x Gir da Fazenda Experimental de Felixlândia (FEFX), da Empresa de Pesquisa Agropecuária de Minas Gerais (EPAMIG), localizada no município de Felixlândia-MG, região central do estado. O clima é classificado, segundo Köppen, como tropical de savana, com duas estações bem distintas: inverno seco (maio a outubro) e verão chuvoso (novembro a abril). A precipitação pluviométrica média anual é de $1.126 \mathrm{~mm}$.

O sistema de produção foi assim caracterizado: durante o período da seca, na época do inverno, as vacas foram confinadas e alimentadas com cana-de-açúcar in natura (Saccharum officinarum L.), enriquecida com ureia e sulfato de amônio, por seis meses. Durante o período chuvoso, na época do verão, as vacas foram mantidas por seis meses em pastos divididos em piquetes, formados por gramíneas Brachiaria decumbens e Brachiaria brizanta. Segundo Gomide et al. (2001), as pastagens de Brachiaria decumbens são capazes de sustentar vacas mestiças com produção média de leite de $11,0 \mathrm{~kg} / \mathrm{cab}$./dia. A suplementação concentrada foi realizada durante a ordenha e de acordo com a produção de leite das vacas, na relação de 1 kg para
$3 \mathrm{~kg}$ de leite produzido, a partir de $5 \mathrm{~kg}$ de leite. A água, em bebedouros e/ou em represas, e a mistura mineral, em cochos cobertos, ficaram à disposição.

Por trinta dias, as vacas no pré-parto recebiam diariamente $0,8 \mathrm{~kg}$ de concentrado no período da seca. Passadas as 24 horas pós-parto, as vacas foram conduzidas para o sistema de vacas em produção. Aquelas com produção acima de $8 \mathrm{~kg}$ de leite por dia foram ordenhadas duas vezes ao dia; as com produção entre 5 e $8 \mathrm{~kg}$ de leite apenas uma vez. Vacas com produção abaixo de $5 \mathrm{~kg}$ de de leite por dia foram soltas com a cria e, quando atingiam 90 dias de pré-parto, foram separadas dos bezerros, ou seja, foram secas. Os bezerros em amamentação foram à sala de ordenha para estimular a descida do leite. Eles eram oriundos de cruzamento terminal e eram vendidos por ocasião do desmame, que ocorreu, em média, aos 276 dias de idade.

Como referência administrativa e para efeito de cálculo considerou-se um sistema hipotético de produção de leite com 68 vacas F1 Holandês x Gir, ordenhadas duas vezes ao dia por dois homens, em sala de ordenha do tipo espinha de peixe com fosso e ala dupla, com quatro vacas de cada lado. A ordenhadeira mecânica foi de sistema aberto com "balde ao pé".

Os cálculos deste estudo foram baseados em dados produtivos (Tabela 1) e reprodutivos (Tabela 2) provenientes do sistema de produção de leite com vacas F1 Holandês $\mathrm{x}$ Gir da FEFX - EPAMIG; em índices técnicos e manejo de vacas F1 Holandês x Gir encontrados na literatura (Tabela 3 ); nos valores relacionados à comercialização de animais e produtos e aos indicadores mercadológicos (Tabela 4); em cotações de preço obtidas no Boletim Cepea (Centro de Estudos Avançados em Economia Aplicada - Região de referência de Minas Gerais); e nos dados econômicofinanceiros deste sistema hipotético de produção de leite, durante o período de 01 de maio de 2011 a 30 de abril de 2012. 
Tabela 1 - Valores de desempenho produtivo de vacas F1 Holandês x Gir em diferentes ordens de partos utilizados neste estudo

\begin{tabular}{ccccc}
\hline $\begin{array}{c}\text { Ordem } \\
\text { de parto }\end{array}$ & $\begin{array}{c}\text { Produção total } \\
(\mathrm{kg})\end{array}$ & $\begin{array}{c}\text { Produção média } \\
\text { diária }(\mathrm{kg})\end{array}$ & $\begin{array}{c}\text { Duração da } \\
\text { lactação }(\text { dias })\end{array}$ & $\begin{array}{c}\text { Produção média } \\
\text { no pico }(\mathrm{kg})\end{array}$ \\
\hline Primeira & $2.426,36^{\mathrm{e}} \pm 710,45$ & $8,14^{\mathrm{a}} \pm 2,03$ & $297,97^{\mathrm{a}} \pm 49,55$ & $13,23^{\mathrm{e}} \pm 3,13$ \\
Segunda & $3.048,47^{\mathrm{d}} \pm 833,12$ & $10,82^{\mathrm{f}} \pm 2,39$ & $280,96^{\mathrm{b}} \pm 42,16$ & $17,32^{\mathrm{d}} \pm 8,31$ \\
Terceira & $3.391,39^{\mathrm{c}} \pm 895,43$ & $11,84^{\mathrm{e}} \pm 2,26$ & $285,57^{\mathrm{b}} \pm 50,39$ & $18,06^{\mathrm{d}} \pm 2,84$ \\
Quarta & $3.646,20^{\mathrm{b}} \pm 874,48$ & $12,92^{\mathrm{d}} \pm 2,16$ & $281,29^{\mathrm{b}} \pm 43,72$ & $19,17^{\mathrm{c}} \pm 3,25$ \\
Quinta & $3.886,23^{\mathrm{a}} \pm 899,45$ & $14,00^{\mathrm{c}} \pm 2,61$ & $278,00^{\mathrm{b}} \pm 43,13$ & $20,76^{\mathrm{b}} \pm 6,65$ \\
Sexta & $4.005,36^{\mathrm{a}} \pm 938,86$ & $14,46^{\mathrm{b}} \pm 2,31$ & $276,29^{\mathrm{b}} \pm 43,97$ & $21,28^{\mathrm{b}} \pm 3,53$ \\
Sétima & $4.033,58^{\mathrm{a}} \pm 810,55$ & $15,20^{\mathrm{a}} \pm 2,51$ & $265,94^{\mathrm{c}} \pm 34,05$ & $22,18^{\mathrm{a}} \pm 3,21$ \\
Oitava & $3.961,23^{\mathrm{a}} \pm 644,66$ & $15,33^{\mathrm{a}} \pm 1,97$ & $259,24^{\mathrm{c}} \pm 34,29$ & $22,13^{\mathrm{a}} \pm 2,90$ \\
Nona & $3.881,94^{\mathrm{a}} \pm 669,57$ & $15,51^{\mathrm{a}} \pm 2,69$ & $251,79^{\mathrm{d}} \pm 29,67$ & $22,23^{\mathrm{a}} \pm 3,10$ \\
\hline
\end{tabular}

Médias seguidas de letras minúsculas distintas na mesma coluna diferem $(\mathrm{p}<0,05)$ pelo teste Scott-Knott

Fonte: Pereira (2012)

Tabela 2 - Índices reprodutivos das vacas F1 Holandês x Gir em função da ordem de parto utilizados neste estudo

\begin{tabular}{ccccc}
\hline $\begin{array}{c}\text { Ordem } \\
\text { de parto }\end{array}$ & $\begin{array}{c}\text { Peso ao } \\
\text { parto }(\mathrm{kg})\end{array}$ & $\begin{array}{c}\text { Período de } \\
\text { serviço (dias) }\end{array}$ & $\begin{array}{c}\text { Intervalo de } \\
\text { partos (dias) }\end{array}$ & $\begin{array}{c}\text { Idade ao } \\
\text { parto (meses) }\end{array}$ \\
\hline Primeiro & $442,4^{\mathrm{d}}$ & $160,4^{\mathrm{a}}$ & $446,0^{\mathrm{a}}$ & 33,7 \\
Segundo & $473,7^{\mathrm{c}}$ & $90,2^{\mathrm{b}}$ & $376,0^{\mathrm{b}}$ & 48,3 \\
Terceiro & $497,2^{\mathrm{b}}$ & $76,2^{\mathrm{b}}$ & $361,4^{\mathrm{b}}$ & 60,7 \\
Quarto & $502,6^{\mathrm{b}}$ & $72,0^{\mathrm{b}}$ & $355,2^{\mathrm{b}}$ & 72,6 \\
Quinto & $500,8^{\mathrm{b}}$ & $89,1^{\mathrm{b}}$ & $375,9^{\mathrm{b}}$ & 84,3 \\
Sexto & $519,9^{\mathrm{a}}$ & $79,9^{\mathrm{b}}$ & $370,1^{\mathrm{b}}$ & 96,6 \\
Sétimo & $529,6^{\mathrm{a}}$ & $96,2^{\mathrm{b}}$ & $382,1^{\mathrm{b}}$ & 108,8 \\
Oitavo & $534,7^{\mathrm{a}}$ & $67,3^{\mathrm{b}}$ & $347,6^{\mathrm{b}}$ & 121,4 \\
Nono & $541,1^{\mathrm{a}}$ & $76,9^{\mathrm{b}}$ & $350,1^{\mathrm{b}}$ & 130,5 \\
\hline
\end{tabular}

Médias seguidas de letras minúsculas distintas na mesma coluna diferem $(\mathrm{p}<0,05)$ pelo teste Scott-Knott Fonte: Oliveira et al. (2012) 
Tabela 3 - Índices técnicos e de manejo de vacas F1 Holandês x Gir encontrados na literatura e utilizados neste estudo

\begin{tabular}{|c|c|}
\hline Itens & Valor \\
\hline Taxa de natalidade ${ }^{1}$ & $98,13 \%$ \\
\hline Intervalo de partos - média 9 partos $^{1}$ & 373,82 dias \\
\hline Taxa de mortalidade de bezerros até 12 meses $^{2}$ & $7,0 \%$ \\
\hline Taxa de mortalidade de novilhas de 12 a 18 meses $^{2}$ & $1,0 \%$ \\
\hline Taxa de mortalidade de novilhas de 18 a 24 meses $^{2}$ & $1,0 \%$ \\
\hline Taxa de mortalidade de vacas - anual $^{2}$ & $1,0 \%$ \\
\hline Produção total na lactação - média 9 partos $^{3}$ & $3.586,75 \mathrm{~kg}$ \\
\hline Duração da lactação - média 9 partos $^{3}$ & 275,23 dias \\
\hline Produção de leite - média por dia $(9 \text { anos })^{3}$ & $13,03 \mathrm{~kg} / \mathrm{dia}$ \\
\hline Peso vaca ao parto - média 9 partos $^{1}$ & 504,66 \\
\hline Taxa de reforma anual - considerando 9 partos & $12 \%$ \\
\hline Consumo de matéria seca cana in natura ${ }^{4}$ & $7,71 \mathrm{~kg}$ \\
\hline Produção de leite/vaca/dia - cana de açúcar in natura ${ }^{4}$ & $11,13 \mathrm{~kg}$ \\
\hline Peso médio do bezerro ao desmame ${ }^{5}$ & $174,6 \mathrm{~kg}$ \\
\hline
\end{tabular}

${ }^{1}$ Oliveira et al. (2012); ${ }^{2}$ Campos; Ferreira (2006); ${ }^{3}$ Pereira (2012); ${ }^{4}$ Santos (2011); ${ }^{5}$ Pereira et al. (2010)

Tabela 4 - Valores relacionados à comercialização de animais e produtos e aos indicadores mercadológicos utilizados neste estudo

\begin{tabular}{|c|c|}
\hline Itens & Valor \\
\hline Comercialização do leite & Preço mensal - Cepea ${ }^{1}$ \\
\hline Bezerro(a) - peso médio $175,6 \mathrm{~kg}$ & @ boi-Cepea ${ }^{1}$ \\
\hline Vaca descarte & $17 @$ vaca-Cepea ${ }^{1}$ \\
\hline Novilhas F1 30 meses - gestante 6 meses & $30 @$ boi-Cepea $^{1}$ \\
\hline Novilhas F1 10 meses - desmamada & $20 @$ boi-Cepea $^{1}$ \\
\hline Concentrado - média do período & $\mathrm{R} \$ 0,63 / \mathrm{kg}$ \\
\hline Relação concentrado: leite (acima de 5 kg leite) & $1: 3$ \\
\hline Aluguel de pasto - mensal & 20\%@boi-Cepea ${ }^{1}$ \\
\hline Custo de produção - cana in natura no cocho ${ }^{2}$ & $\mathrm{R} \$ 51,00 /$ ton. \\
\hline Mão de obra contratada - por pessoa por mês & $\mathrm{SM}+36,8 \%$ de encargos \\
\hline Salário mínimo (SM) - 2011 & $\mathrm{R} \$ 545,00$ \\
\hline Índice de correção de 11/2011 a 09/2013 (IGP-M) & 1,1222637 \\
\hline Taxa real de juros - mensal & $0,5 \%$ \\
\hline Remuneração do empresário & $\mathrm{R} \$ 0,00$ \\
\hline Área do sistema de produção & 10 ha \\
\hline Terra por ha & $\mathrm{R} \$ 10.000,00$ \\
\hline Arrendamento - referência & 1 litro leite/dia/ha \\
\hline
\end{tabular}

${ }^{1}$ Cepea. Região de referência: Minas Gerais (MG)

${ }^{2}$ Valor médio praticado na região no período do estudo 
Para analisar a rentabilidade, primeiramente foi definida a infraestrutura do sistema hipotético de produção de leite e realizado o inventário (cadastro de todos os bens móveis e benfeitorias, bem como as suas particularidades: data e valor de aquisição, vida útil e valor de sucata). Segundo Lopes et al. (2004), o inventário consiste da verificação da existência de bens, da descrição detalhada dos aspectos físicos, da classificação em grupos conforme sua categoria específica (benfeitorias, equipamentos, ferramentas, máquinas, móveis, rebanho, semoventes, veículos e implementos) e da avaliação do valor monetário, conforme o estado de uso.

As informações relacionadas às despesas (mão de obra, alimentação, sanidade etc.) e às receitas (leite e animais) foram estimadas conforme literatura e registradas em planilhas eletrônicas apropriadas para esse fim. As informações mensais relacionadas aos indicadores mercadológicos exigidas pelo software (valor para remuneração do empresário, valor do arrendamento da terra, taxa real de juros mensal e valor da terra) foram definidas conforme valores vigentes de mercado.

O inventário bem como as despesas, as receitas e os demais dados foram cadastrados no software CUSTO BOVINO LEITE 1.0 (LOPES et al., 2002) visando obter a análise de rentabilidade. Tal software contempla as metodologias de custo total de produção (clássica), que envolve o custo fixo e variável, utilizada por Barros (1948), e custo operacional, proposta por Matsunaga et al. (1976).

No sistema hipotético de produção de leite sem o pagamento por qualidade de leite, não houve nenhum critério definido para a produção de um leite com qualidade e, como não houve melhora na qualidade do leite, não foi considerada bonificação paga ao pecuarista. Portanto, foi considerado o manejo tradicional usualmente utilizado em sistema de produção de leite não especializado, onde não se preocupa com a qualidade do leite e, consequentemente, o valor recebido do leite é mínimo e sem bonificação, o chamado "leite cota". A simulação foi considerar, no sistema hipotético de produção de leite com o pagamento por qualidade de leite, os resultados alcançados com a introdução de medidas de higiene e prevenção (pré e pós dipping, vacinação e tratamento de vacas secas) na rentabilidade do sistema de produção de leite com vacas F1 Holandês x Gir. Estas medidas culminaram na melhora da qualidade do leite e na bonificação por qualidade, que foi determinada pelo mercado e serviu como diferencial de remuneração do leite.

Assim sendo, considerou-se que o inventário e as informações dos indicadores mercadológicos (taxa real de juros, remuneração do empresário etc.) foram iguais às duas alternativas. As despesas referentes à produção de leite foram maiores com a introdução de medidas de higiene e prevenção e foram estimadas em $\mathrm{R} \$ 0,006$ por litro de leite produzido. Vale ressaltar que não houve monitoramento (cultura, antibiograma e contagem de células somáticas no tanque e/ou individuais) em nenhuma das alternativas e que as medidas curativas foram semelhantes nas duas alternativas, portanto não foram consideradas como despesas adicionais.

Quanto às receitas, estimou-se aumento de $8,78 \%$ no valor do preço do leite produzido em função da qualidade do leite e da bonificação determinada pelo mercado, conforme Pinheiro (2012). Para esta estimativa foi considerado o valor pago pela Cooperativa Central dos Produtores Rurais de Minas Gerais (CCPR) no período, onde as bonificações foram assim determinadas: $\mathrm{R} \$ 0,0386$ por litro de leite, quando a UFC estava entre 20.000 a 30.000 por $/ \mathrm{mL}$ e $\mathrm{R} \$ 0,0400$ por litro de leite, quando a CCS estava abaixo de 250.000 por $\mathrm{mL}$; totalizando $\mathrm{R} \$ 0,0786$ por litro de leite, equivalente a 
$8,78 \%$ de aumento em relação ao valor do preço do "leite cota". Vale salientar que as bonificações de $\mathrm{R} \$ 0,0318$ por litro de leite, quando a gordura era de $3,75 \%$ e de $\mathrm{R} \$ 0,0300$ por litro de leite, quando a proteína era de $3,25 \%$, não foram computadas como receita, pois a introdução de medidas de higiene e prevenção não interferem nestes quesitos.

Os resultados gerados foram tabulados em planilha eletrônica desenvolvida no MS
Excel $^{\circledR}$ e comparados por meio de análises estatísticas descritivas (LOPES et al., 2009).

\section{RESULTADOS E DISCUSSÃO}

Um resumo da análise de rentabilidade da atividade leiteira de um sistema de produção de leite com vacas F1 Holandês x Gir considerando a qualidade do leite como diferencial de remuneração sobre a

Tabela 5 - Comparativo dos resumos das análises de rentabilidades da atividade leiteira de um sistema de produção de leite com vacas F1 Holandês x Gir sem e com o pagamento por qualidade de leite, no período de maio de 2011 a abril de 2012

\begin{tabular}{|c|c|c|c|}
\hline Especificação & $\begin{array}{c}\text { Sem pagamento } \\
\text { por qualidade }\end{array}$ & $\begin{array}{c}\text { Com pagamento } \\
\text { por qualidade }\end{array}$ & $\begin{array}{c}\% \text { de } \\
\text { variação }\end{array}$ \\
\hline Receitas (R\$) & $230.403,04$ & $246.417,27$ & 6,95 \\
\hline Leite $(\mathrm{R} \$)$ & $182.337,29$ & $198.351,52$ & 8,78 \\
\hline Animais $(\mathrm{R} \$)$ & $48.065,75$ & $48.065,75$ & 0,00 \\
\hline Outras receitas $(\mathrm{R} \$)$ & 0,00 & 0,00 & 0,00 \\
\hline Custo operacional total (COT) $(\mathrm{R} \$)$ & $145.348,96$ & $146.571,23$ & 0,84 \\
\hline Custo operacional efetivo (COE) (R\$) & $123.171,04$ & $124.393,31$ & 0,99 \\
\hline Custo com depreciação (CD) (R\$) & $22.177,92$ & $22.177,92$ & 0,00 \\
\hline Mão de obra familiar (R\$) & 0,00 & 0,00 & 0,00 \\
\hline Custo total (CT) $(\mathrm{R} \$)$ & $170.325,95$ & $171.566,73$ & 0,73 \\
\hline Custos fixos (CF) (R\$) & $46.065,49$ & $46.065,49$ & 0,00 \\
\hline Remuneração da terra (R\$) & 112,00 & 112,00 & 0,00 \\
\hline Remuneração do capital investido ( $\mathrm{R} \$$ ) & $22.832,31$ & $22.832,31$ & 0,00 \\
\hline Remuneração do empresário (R\$) & 0,00 & 0,00 & 0,00 \\
\hline Impostos considerados fixos $(\mathrm{R} \$)$ & 943,26 & 943,26 & 0,00 \\
\hline Depreciação (R\$) & $22.177,92$ & $22.177,92$ & 0,00 \\
\hline Custos variáveis (CV) (R\$) & $124.260,46$ & $125.501,24$ & 1,00 \\
\hline Custo operacional efetivo (s/imp.) (R\$) & $122.227,78$ & $123.450,05$ & 1,00 \\
\hline Remuneração do capital de giro $(\mathrm{R} \$)$ & $2.032,68$ & $2.051,19$ & 0,91 \\
\hline Mão de obra familiar (R\$) & 0,00 & 0,00 & 0,00 \\
\hline Margem bruta $(\mathrm{R} \$)$ & $108.175,26$ & $122.967,22$ & 13,67 \\
\hline Margem líquida $(\mathrm{R} \$)$ & $85.054,08$ & $99.846,04$ & 17,39 \\
\hline Resultado (lucro ou prejuízo)(R\$) & $60.077,09$ & $74.850,54$ & 24,59 \\
\hline Lucratividade $(\%)$ & 26,07 & 30,38 & 16,53 \\
\hline Rentabilidade $(\%)$ & 9,80 & 12,19 & 24,39 \\
\hline Quantidade total de leite produzido (kg) & $211.327,00$ & $211.327,00$ & 0,00 \\
\hline
\end{tabular}


rentabilidade dos sistemas de produção de leite com vacas F1 Holandês x Gir pode ser observado na Tabela 5. Houve um incremento de $\mathrm{R} \$ 16.014,23$ na receita, equivalente a $6,95 \%$. A contribuição da venda de leite na receita total elevou $8,78 \%$, mostrando a influência do diferencial de remuneração do leite na receita. A quantidade de leite produzida no período continuou a mesma, ou seja, $211.327 \mathrm{~kg}$. Contudo, o aumento da receita está relacionado à maior remuneração pela qualidade do leite e não pelo aumento do volume produzido e vendido. Conforme Machado (2008), com o cumprimento das exigências de padrões de qualidade do leite haverá maior valorização do produto ao produtor e um aumento na eficiência industrial culminando num produto final de melhor qualidade e sem risco para o consumidor, o que representa uma revolução para toda a cadeia produtiva do leite.

O custo operacional total (COT) elevou $0,84 \%$, valor bastante inexpressivo se comparado ao aumento da receita, que foi de $6,95 \%$. O custo operacional efetivo (COE) elevou em $0,99 \%$. Por $\mathrm{kg}$ de leite produzido, o aumento foi de $\mathrm{R} \$ 0,006$, valor bem abaixo de $\mathrm{R} \$ 0,0215$ mencionado por Lopes et al. (2012), em estudo com um rebanho de 100 vacas holandesas em lactação, com produção diária de $20 \mathrm{~kg}$ e com $1 \%$ de mastite clínica. Esta discrepância pode ser justificada porque estes autores, além das despesas de prevenção (pré e pós dipping, vacinação e tratamento de vacas secas), utilizaram medidas de monitoramento como cultura e antibiograma, contagem de células somáticas no tanque (CCST) e contagem de células somáticas individuais (CCSI); medidas estas mais onerosas. Contudo, segundo estes autores, as medidas preventivas mostraram-se excelente relação custo/beneficio. Miller et al. (1993) estimaram valores de US\$14,50 por vaca/ano para o COE da prevenção, valor de $\mathrm{R} \$ 0,004 / \mathrm{kg}$ de leite, se convertido em reais, bastante semelhante ao encontrado neste presente estudo.
Como era de se esperar, houve um acréscimo na margem bruta, na margem líquida e, consequentemente, no resultado final, que, por sua vez, foi positivo. O lucro aumentou em $\mathrm{R} \$ 14.773,45$, passando de $\mathrm{R} \$ 60.077,09$ para $\mathrm{R} \$ 74.850,54$ no período analisado, equivalente a $24,59 \%$. A lucratividade passou de $26,07 \%$ para $30,38 \%$ e a rentabilidade de $9,8 \%$ para $12,19 \%$, correspondente a um aumento de $16,53 \%$ e $24,39 \%$, respectivamente. Vale dizer que tanto a lucratividade como a rentabilidade foram ainda melhores do que nos valores apresentados, pois o cálculo foi feito considerando o custo total (CT) e nele já estão computadas as remunerações com terra, sobre capital investido e sobre o capital de giro.

$\mathrm{Na}$ Tabela 6, pode-se observar que, apesar do mesmo volume de leite produzido com ou sem o uso desta prática zootecnica, a relação depreciação/COT teve uma ligeira diminuição, tendo em vista o pequeno aumento do COE e, consequentemente, da relação COE/COT, proporcionado pelo aumento de $0,99 \%$ nos gastos.

O ponto de equilíbrio passou de 459,23 para $366,11 \mathrm{~kg}$ de leite por dia, equivalente a uma diminuição de $20,28 \%$; valor este bastante considerável, mostrando que, com o significativo aumento no preço de venda do leite, menor foi a quantidade a ser produzida para se igualar os custos totais às receitas.

Considerando a composição do $\mathrm{COE}$ (Tabela 7), pode-se constatar que não houve diferença de valores percentuais entre os sistemas estudados, a despeito de ter tido uma diferença mínima em reais. Além do baixo gasto com o uso desta prática zootécnica, o alto volume de leite produzido fez com que essa diferença não aparecesse nos valores quando se usaram duas casas decimais.

Vale destacar que os itens que normalmente mais interferem nos custos, a alimentação e a mão de obra, também se mantiveram iguais e que a elevação dos gastos com os materiais utilizados com as medidas 
preventivas para obtenção do leite com maior qualidade foi muito pequena. De acordo com Lopes et al. (2012), a adoção e o investimento em medidas preventivas deve receber grande atenção por parte dos técnicos e pecuaristas.

Tabela 6 - Índices técnicos/gerenciais de um sistema de produção de leite sem e com o pagamento por qualidade de leite no período de maio de 2011 a abril de 2012

\begin{tabular}{lcc}
\hline \multicolumn{1}{c}{ Especificação } & $\begin{array}{c}\text { Sem pagamento } \\
\text { por qualidade }\end{array}$ & $\begin{array}{c}\text { Com pagamento } \\
\text { por qualidade }\end{array}$ \\
\hline Depreciação / COT (\%) & 15,26 & 15,13 \\
COE / COT (\%) & 84,09 & 84,23 \\
Mão de obra familiar / COT (\%) & 0,00 & 0,00 \\
Custo fixo / Custo total (\%) & 27,05 & 26,85 \\
Custo variável / Custo total (\%) & 72,95 & 73,15 \\
Depreciação / Custo total (\%) & 13,02 & 12,93 \\
Produtividade animal / dia (kg de leite) & 11,58 & 11,58 \\
Produtividade animal / ha/ ano (kg de leite) & $21.132,70$ & $21.132,70$ \\
Produção diária vendida (kg de leite) & 578,98 & 578,98 \\
Produção diária (kg de leite) & 578,98 & 578,98 \\
Ponto de equilíbrio /kg leite / dia (kg de leite) & 459,23 & 366,11 \\
Quantidade de vacas em lactação / ha (un) & 5,00 & 5,00 \\
Produção de leite / mão de obra (kg / serviço) & 289,49 & 289,49 \\
Relação matrizes / homem (un) & 34,00 & 34,00 \\
Relação total do rebanho / homem (un) & 65,00 & 65,00 \\
Quantidade de mão de obra (un) & 2,00 & 2,00 \\
\hline
\end{tabular}

Tabela 7 - Representatividade de cada grupo no custo operacional efetivo do sistema de produção de leite sem e com o pagamento por qualidade de leite, em \%, no período de maio de 2011 a abril de 2012

\begin{tabular}{lcc}
\hline Especificação & $\begin{array}{c}\text { Sem pagamento } \\
\text { por qualidade }\end{array}$ & $\begin{array}{c}\text { Com pagamento } \\
\text { por qualidade }\end{array}$ \\
\hline Alimentação & 44,60 & 44,60 \\
Concentrado & 21,48 & 21,48 \\
Sal mineral & 1,05 & 1,05 \\
Volumoso & 22,07 & 22,07 \\
Mão de obra & 14,64 & 14,64 \\
Sanidade & 3,67 & 3,67 \\
Ordenha & 4,89 & 4,89 \\
Reprodução & 1,75 & 1,75 \\
Energia & 4,32 & 4,32 \\
Despesas diversas & 26,14 & 26,14
\end{tabular}


Entretanto, a maior diferença para o resultado favorável no uso dessa prática zootécnica se dá, principalmente, pela qualidade e empenho da mão de obra. Contudo, é importante destacar a necessidade do treinamento da mão de obra para atingir os parâmetros necessários para se obter melhor bonificação.

Os custos médios de produção (Tabela 8) não apresentaram diferenças de valores percentuais entre os sistemas estudados, embora tenha havido uma diferença mínima em reais. Ao subtrair o custo total do preço médio do leite, pode-se observar que houve lucro de $\mathrm{R} \$ 0,05$ por $\mathrm{kg}$ de leite do "sistema de produção base" e de R $\$ 0,13$ do sistema com o uso desta prática zootécnica, cujo preço médio do leite com a bonificação pago pela indústria $(\mathrm{R} \$ 0,94)$ foi o grande e significativo diferencial.

Constata-se, em nível de mercado, que o preço pago por alguns laticínios para o leite in natura considera a qualidade do mesmo, sendo que a bonificação pode chegar até $20 \%$ do valor total recebido. São consideradas bonificações para contagem bacteriana (até 4,7\%), contagem de células somáticas (até $3,5 \%$ ), percentual de gordura (até 5,9\%) e percentual de proteína (até 5,9\%). Cardoso et al. (2004) verificaram que o resultado econômico da produção de leite é negativo, ou seja, dá prejuízo, e que é preciso haver a bonificação dos seus componentes para reverter a situação.

\section{CONCLUSÕES}

A utilização de práticas zootécnicas que possibilitam melhorias na qualidade do leite, proporcionando um diferencial da remuneração, advinda das bonificações, incrementa os resultados econômico-financeiros e melhora a rentabilidade do sistema de produção de leite com vacas $\mathrm{F} 1$ Holandês $\mathrm{x}$ Gir confinadas durante o período da seca e alimentadas com cana-de-açúcar in natura (Saccharum officinarum L.), enriquecida com ureia e sulfato de amônio.

\section{AGRADECIMENTOS}

Os autores agradecem à FAPEMIG (Fundação de Amparo à Pesquisa do Estado de Minas Gerais) pelo apoio na realização desta pesquisa (PPM 00281-13).

\section{REFERÊNCIAS}

BARROS, H. Economia agrária. Lisboa: Sá da Costa, 1948. 348 p.

BRASIL. Ministério da Agricultura, Pecuária e Abastecimento. Departamento de Inspeção de Produtos de Origem Animal. Instrução

Tabela 8 - Custos médios de produção, por quilograma de leite, do sistema de produção de leite sem e com o pagamento por qualidade de leite, em $\mathrm{R} \$ / \mathrm{kg}$, no período de maio de 2011 a abril de 2012

\begin{tabular}{lcc}
\hline \multicolumn{1}{c}{ Especificação } & $\begin{array}{c}\text { Sem pagamento } \\
\text { por qualidade }\end{array}$ & $\begin{array}{c}\text { Com pagamento } \\
\text { por qualidade }\end{array}$ \\
\hline Preço médio do leite & 0,86 & 0,94 \\
Custo operacional total & 0,69 & 0,69 \\
Custo operacional efetivo & 0,58 & 0,58 \\
Custo total & 0,81 & 0,81 \\
Custo fixo & 0,22 & 0,22 \\
Custo variável & 0,59 & 0,59 \\
\hline
\end{tabular}


Normativa $\mathrm{n}^{\circ} 62$, de 26 de agosto de 2003. Oficializa os métodos analíticos oficiais para análises microbiológicas para controle de produtos de origem animal e água. Diário Oficial da República Federativa do Brasil, Brasília, 18 set. 2003. Seção 1, p. 14.

CAMpos, A. L. T.; FERREIRA, A. M. Composição no rebanho e sua importância no manejo. Instrução técnica para o produtor de leite. Embrapa, 2006. Disponível em: http:// www.cnpgl.embrapa.br/pastprod/32Instrucao. pdf. Acesso em: 09 fev. 2013.

CARDOSO, V. L. et al. Objetivos de seleção e valores econômicos de características de importância econômica para um sistema de produção de leite a pasto na região sudeste. Revista Brasileira de Zootecnia, v. 33, n. 2, p. 320-327, 2004.

GOMIDE, J. A. et al. Consumo e produção de leite de vacas mestiças em pastagem de brachiaria decumbens manejadas sob duas ofertas diárias de forragem. Revista Brasileira de Zootecnia, v. 30, n. 4, p. 1194-1199, 2001.

LOPES, M.A.; CAMPELLO; R. P.; CARVALHO, F. M. Custo bovino leite 1.0: software de controle de custos para a atividade leiteira. Revista Brasileira Agroinformática, v. 4, n. 2, p. 102-115, 2002.

LOPES, M. A. et al. Avaliação do impacto econômico da mastite em rebanhos bovinos leiteiros. Arquivos do Instituto Biológico, v. 79, n. 4, p. 477-483, 2012.

LOPES, M. A. et al. Resultados econômicos de sistemas de produção de leite com diferentes níveis tecnológicos na região de Lavras (MG) nos anos 2004 e 2005. Ciência e Agrotecnologia, v. 33, n. 1, p. 252-260, 2009.

LOPES, M. A. et al. Controle gerencial e estudo da rentabilidade de sistemas de produção de leite na região de Lavras (MG). Ciência e Agrotecnologia, v. 28, n. 4, p. 883-892, 2004.
MACHADO, P. F. Pagamento do leite por qualidade. In: CONGRESSO BRASILEIRO DE QUALIDADE DO LEITE, 3., 2008, Recife. Anais... Recife: CCS Gráfica e Editora, 2008. $373 \mathrm{p}$.

MATSUNAGA, M.; BEMELMANS, P. F.; TOLEDO, P. E. N. Metodologia de custo de produção utilizado pelo IEA. São Paulo: Agricultura em São Paulo, 1976. p. 123-139.

MILLER, R. H.; PAAPE, M. J.; FULTON, L. A. The relationship of milk somatic cell count to milk yields for holstein heifers after first calving. Journal of Dairy Science, v. 76, n. 3, p. 728-733, 1993.

OLIVEIRA, P. A.; RUAS, J. R. M.; FROTA, L. M. Avaliação de características produtivas e reprodutivas de vacas F1 Holandês x Gir. In: SEMINÁRIO DE INICIAÇÃO CIENTÍFICA E TECNOLÓGICA, 9., 2012, Belo Horizonte. Anais... Belo Horizonte: Epamig, 2012. v. 1, p. 1-4.

PEREIRA, M. E. G. Produção de leite de quatro grupos genéticos f1 holandês $x$ zebu. 2012. 78 p. Dissertação (Mestrado em Zootecnia) - Universidade Estadual de Montes Claros, Janaúba, 2012.

PEREIRA, M. E. G. et al. Avaliação da produção de bezerros de corte em um rebanho leiteiro F1 Holandês x Zebu. In: REUNIÃO ANUAL DA SOCIEDADE BRASILEIRA DE ZOOTECNIA, 47., 2010, Salvador. Anais... Salvador: SBZ, 2010. 1 CD-ROM.

PINHEIRO, F. F. Pagamento por qualidade - Remuneração como Incentivo à Qualidade do Leite. 2012. Disponível em: <http://www. ccprleite.com.br/pagina/1211/pagamento-porqualidade.aspx>. Acesso: em 09 fev. 2014.

SANTOS, S. A. Curvas de lactação e consumo de vacas $F 1$ Holandês $x$ Zebu em pastejo e confinamento. 2011. 212 p. Tese (Doutorado) - Universidade Federal de Viçosa, Viçosa, 2011. 